\title{
Analysis of the Mouse and Human acyl-CoA Thioesterase (ACOT) Gene Clusters Shows That Convergent, Functional Evolution Results in a Reduced Number of Human Peroxisomal ACOTs.
}

\author{
Mary Hunt \\ Technological University Dublin, mary.hunt@tudublin.ie \\ Anna Rautanen \\ Karolinska Institute \\ Maria Westin \\ Karolinska Institute
}

See next page for additional authors

Follow this and additional works at: https://arrow.tudublin.ie/scschbioart

Part of the Biochemistry Commons, Bioinformatics Commons, and the Molecular Biology Commons

\section{Recommended Citation}

Hunt, M. C., Rautanen, A., Westin, M. A. K., Svensson, L. T., Alexson, S. E. H. Analysis of mouse and human acyl-CoA thioesterase (ACOT) gene clusters shows that convergent functional evolution results in a reduced number of peroxisomal ACOTs. FASEB (2006) 20 (11) 1855-1864. doi:10.1096/fj.06-6042com

This Article is brought to you for free and open access by the School of Biological Sciences at ARROW@TU Dublin. It has been accepted for inclusion in Articles by an authorized administrator of ARROW@TU Dublin. For more information, please contact arrow.admin@tudublin.ie, aisling.coyne@tudublin.ie,gerard.connolly@tudublin.ie.

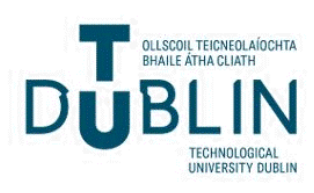


Authors

Mary Hunt, Anna Rautanen, Maria Westin, Thomas Svensson, and Stefan Alexson

This article is available at ARROW@TU Dublin: https://arrow.tudublin.ie/scschbioart/11 


\title{
Analysis of the mouse and human acyl-CoA thioesterase (ACOT) gene clusters shows that convergent, functional evolution results in a reduced number of human peroxisomal ACOTs.
}

\author{
Mary C. Hunt, \#\#Anna Rautanen, Maria A. K. Westin, \#L. Thomas \\ Svensson, and Stefan E. H. Alexson.
}

Karolinska Institutet, Department of Laboratory Medicine, Division of Clinical Chemistry

C1-74, Karolinska University Hospital at Huddinge, SE-141 86 Stockholm, Sweden. Present address: \#\#Finnish Genome Center, University of Helsinki, 00014 Helsinki, Finland and \#Biovitrum AB, Arvid Wallgrens Backe 20, SE-413 46 Göteborg, Sweden.

Running title: Human and mouse acyl-CoA thioesterase gene clusters.

Address correspondence to

Dr Mary Hunt,

Karolinska Institutet,

Department of Laboratory Medicine,

Division of Clinical Chemistry C1-74,

Karolinska University Hospital at Huddinge,

SE-141 86 Stockholm,

Sweden.

Phone: +46-8-58581293

Fax: $+46-8-58581260$

E-mail: mary.hunt@ki.se 


\section{ABSTRACT}

The maintenance of cellular levels of free fatty acids and acyl-CoAs, the activated form of free fatty acids, is extremely important as imbalances in lipid metabolism have serious consequences for human health. Acyl-CoA thioesterases (ACOTs) hydrolyze acyl-CoAs to the free fatty acid and $\mathrm{CoASH}$, and thereby have the potential to regulate intracellular levels of these compounds. We have previously identified and characterized a mouse ACOT gene cluster, comprised of six genes that apparently arose by gene duplications, encoding acylCoA thioesterases with localizations in cytosol (ACOT1), mitochondria (ACOT2) and peroxisomes (ACOT3-6). However, the corresponding human gene cluster contains only three genes, ACOT1, ACOT2 and ACOT4 coding for full-length thioesterase proteins, of which only one is peroxisomal (ACOT4). We therefore set out to characterize the human genes, and we here show that the human ACOT4 protein catalyzes the activities of three mouse peroxisomal ACOTs (ACOT3, 4, and 5), being active on succinyl-CoA and mediumto long-chain acyl-CoAs, while ACOT1 and ACOT2 carry out similar functions to the corresponding mouse genes. These data strongly suggest that the human ACOT4 gene has acquired the functions of three mouse genes by a functional convergent evolution that also provides an explanation for the unexpectedly low number of human genes.

Keywords: $\beta$-oxidation, acyl-CoA, peroxisome, fatty acids. 


\section{INTRODUCTION}

Imbalances in fatty acid metabolism have serious consequences for human health and the onset and progression of several chronic diseases, such as coronary artery disease and atherosclerosis, dyslipidemia, obesity and diabetes. The central role of free fatty acids and acyl-CoAs (the activated form of fatty acids) is evident by the numerous intracellular processes in which these molecules are key components. These processes (reviewed in (1)) include oxidation of fatty acids ( $\alpha \beta$ and $\omega$-oxidation), biosynthesis of lipids, and allosteric regulation of a number of enzymes (2-4) and opening of $\mathrm{K}_{\mathrm{ATP}}$-channels in human pancreatic beta-cells (5). There are, however, many processes that are activated by acyl-CoAs and inhibited by the free fatty acids or vice versa, showing the importance of maintaining the balance of these compounds in-vivo. It has recently been shown that palmitoyl-CoA inhibits AMP-activated protein kinase (AMPK) indirectly, by a specific and concentration dependent inactivation of its-upstream kinase (6). Another example where the balance of free fatty acids versus acyl-CoAs is important, is in the activation of the peroxisome proliferator-activated receptors (PPARs) by free fatty acids (7-10) and more recently also by CoA esters of longchain fatty acids (acyl-CoAs) (11). A recently recognized way in which the cell can control the intracellular acyl-CoA and free fatty acid levels is via the activity of enzymes named acyl-CoA thioesterases (ACOTs), which can hydrolyze acyl-CoAs to the corresponding free fatty acid and coenzyme A (CoASH) (for reviews see $(12,13)$ ). These acyl-CoA thioesterases are expressed in several cellular compartments that coincide with metabolic processes involving acyl-CoAs.

In 1995, a particular family of acyl-CoA thioesterases was identified in rat and was named Type-I acyl-CoA thioesterases (14). In the past few years, the cloning of cDNAs and genes have identified the Type-I acyl-CoA thioesterases to be a novel gene family with six members in mouse, a cytosolic isoform (Acot1, previously CTE-I), a mitochondrial isoform (Acot2, previously MTE-I), and four peroxisomal isoforms (Acot 3, 4, 5 and 6, previously PTE-Ia, -Ib, -Ic, and -Id) (15-17). Both the sequence similarity and the gene organization show a very high degree of conservation, suggesting that these genes have evolved by gene duplications. The identification of four peroxisomal ACOTs was surprising, but the characterization of their acyl-CoA substrate specificities showed that they catalyze distinct activities, and also show individual tissue expression. However, based on the multiple and important functions that peroxisomes play in degradation of a variety of lipids, which is 
reflected in the severity of peroxisomal disorders (for reviews, $(18,19)$ ), it is tempting to speculate that these ACOTs participate in regulation of $\beta$-oxidation and release of $\beta$ oxidation products. In mouse, this Type-I gene cluster is located on mouse chromosome 12 D3 within $120 \mathrm{~kb}$ of DNA. We have now characterized the genes in the corresponding gene cluster of Type-I ACOTs in human, which is localized on human chromosome 14q24.3. However, this cluster contains four genes of which three genes are transcribed to encode fulllength ACOTs and only one gene encodes a peroxisomal acyl-CoA thioesterase (ACOT4). We here show that the human ACOT4 gene apparently has evolved into a multifunctional protein that catalyzes the combined activities of mouse ACOT3, 4 and 5, while human ACOT1 and ACOT2 have similar functions to the mouse orthologs.

\section{MATERIALS AND METHODS}

\section{Cloning and expression of acyl-CoA thioesterases}

Oligonucleotides were designed based on the sequence of the ORFs for human ACOT1, ACOT2, and ACOT4. Due to the very high sequence identity between ACOT1 and ACOT2 it was not possible to PCR amplify individual transcripts of ACOT1 and ACOT2. We obtained the ACOT2 ORF using PCR amplification from human liver and purchased a clone containing the cDNA for ACOT1, Accession No. BM543491, (Image clone No. 5726581, UK HMGP Resource centre, Hinxton, UK) and used this as a template for PCR amplification of ACOT1. ACOT1 and ACOT2 were cloned into pET16b (Novagen Inc., Darmstadt, Germany) using the following primers: 5'-CATATGTCACTTTTGATGGGATTGTC-3' and 5'-CATATGGCGGCGACGCTGAT-3' with NdeI sites indicated in bold. The ACOT4 was cloned into the pET102 (Invitrogen Corp., California, USA), in frame with thioredoxin. The 5' primer sequence was 5'-CACCATGTCAGCAACGCTGATCCTG-3' and was constructed to contain an overhang of CACC for cloning into pET102. The 3' primer sequence was 5'CAATTTAGGGACAGCTGTTTTCTG-3'. The ORF for ACOT4 was amplified by RT-PCR from human liver total RNA. RT-PCR was performed in a Perkin-Elmer 2600 using the One Step RT-PCR kit (Takara Biomedicals, Shiga, Japan). Thermal cycling was performed at $50^{\circ} \mathrm{C}$ for $30 \mathrm{~min}$ and $94^{\circ} \mathrm{C}$ for $2 \mathrm{~min}$, followed by 35 cycles of $94^{\circ} \mathrm{C}$ for $30 \mathrm{sec}, 51.5^{\circ} \mathrm{C}$ for 30 $\sec (\mathrm{ACOT} 2)$ or $60^{\circ} \mathrm{C}$ for $30 \mathrm{sec}$ (ACOT4) and $72^{\circ} \mathrm{C}$ for $3 \mathrm{~min}$. The resultant PCR products were cloned into pET102 or pET16b respectively and sequenced (Cybergene AB, Huddinge, Sweden). 
The plasmids containing the human ACOT1, 2 and 4 were then used to transform BL21(DES3)pLysS cells (Novagen Inc., Darmstadt, Germany). Bacteria were cultured in 500 $\mathrm{ml}$ Luria-Bertani medium at $37^{\circ} \mathrm{C}$ with addition of ampicillin $(50 \mu \mathrm{g} / \mathrm{ml})$ and chloramphenicol $(34 \mu \mathrm{g} / \mathrm{ml})$ until the $\mathrm{OD}_{600 \mathrm{~nm}}$ was approximately 0.6 . Protein expression was induced by addition of $1 \mathrm{mM}$ isopropyl-1-thio- $\beta$-D-galactopyranoside and cells were grown for 3 hours at $37^{\circ} \mathrm{C}$ (ACOT1 and ACOT2) or at $30^{\circ} \mathrm{C}$ for $5 \mathrm{~h}$ (ACOT4). The recombinant proteins were purified as described previously and eluted using $500 \mathrm{mM}$ imidazole (20). The purity of the expressed proteins was examined using SDS/PAGE analysis and Coomassie Brilliant blue staining and these purified proteins were used to measure acyl-CoA thioesterase activity. Mouse ACOT3, 4 and 5 recombinant proteins were produced as outlined in $(16,17)$ and activity measured with various acyl-CoA substrates.

\section{Northern blot analysis}

Human Multiple Tissue blots were purchased from Clontech Inc (Palo Alto, California, USA), and analysis was carried out according to the Manufacturers instructions, using $\alpha-32 \mathrm{P}-$ labeled cDNA probes. The cDNA probes for the human ACOTs were constructed using RTPCR from human liver total RNA. For ACOT1 and ACOT2, a cDNA probe was amplified corresponding to amino acids 167-371 of the open reading frame (ORF) (shown in Fig. 2). The ACOT4 cDNA probe was amplified corresponding to amino acids 215 to 405 of the ORF and a specific probe located in the mitochondrial targeting signal of ACOT2 was amplified corresponding to amino acids 21 to 59 of the ORF.

\section{Enzyme activity measurements}

ACOT activity was measured spectrophotometrically at $412 \mathrm{~nm}$ with 5,5'-dithiobis(2nitrobenzoic acid) (DTNB). The medium contained $200 \mathrm{mM}$ potassium chloride, $10 \mathrm{mM}$ HEPES and $0.05 \mathrm{mM}$ DTNB (pH 7.4). An $\mathrm{E}_{412}=13,600 \mathrm{M}^{-1} \mathrm{~cm}^{-1}$ was used to calculate the activity. The acyl-CoA substrates used were obtained from Sigma-Aldrich Inc. (St. Louis, USA). The addition of bovine serum albumin (BSA) to prevent substrate inhibition with CoA esters was titrated for long-chain acyl-CoAs (C16-C20-CoA). A BSA:C18-CoA molar ratio of 1.8:1 was used in measuring ACOT1 and ACOT2 activities. Otherwise addition of BSA was not required for measurement of acyl-CoA thioesterase activity. 


\section{Cellular localization of human ACOTs using green fluorescent fusion protein}

The ORFs for the human ACOT1, 2, 4 and 6 were cloned as fusion proteins with green fluorescent protein (GFP) to examine the intracellular localization of the proteins. ACOT6 was amplified using primers 5'-ATGCTGCAGCATCCAAAGGTG-3' and 5'TCTGTCAAGCACAGCAAAATATAA-3'. The ORFs were amplified using PCR and the PCR products for ACOT1, ACOT4 and ACOT6 were cloned into the pcDNA3.1/NT-GFP vector (Invitrogen Corp., California, USA), in-frame with the GFP, leaving the carboxyterminal end accessible. The ACOT2 was cloned in-frame with the pcDNA3.1/CTGFP (Invitrogen Corp., California, USA), leaving the N-terminal end accessible. Sequence analysis was performed using Big Dye Terminator Ready Reaction kit (Perkin Elmer Inc., Wellesley, MA, USA) and was sequenced by Cybergene AB (Huddinge, Sweden).

Human skin fibroblasts or HepG2 cells were grown in Eagles MEM (Sigma-Aldrich Inc., St. Louis, USA), supplemented with 10\% fetal calf serum (Invitrogen Corp., California, USA) and $100 \mathrm{U}$ penicillin/100 $\mu \mathrm{g}$ streptomycin in an atmosphere of $5 \% \mathrm{CO}_{2}$. Cells were grown overnight in $60 \mathrm{~mm}$ dishes on glass coverslips and were transfected with $10 \mu \mathrm{g}$ of the various plasmids using Calcium Phosphate method as described previously (20). The localization of ACOT1, ACOT4 and ACOT6 was investigated in fibroblasts, and in the case of ACOT4, skin fibroblasts from a Zellweger patient were also used. The localization of ACOT2 was investigated in HepG2 cells and Mitotracker ${ }^{\circledR}$ Orange CMTMRos (Invitrogen Corp., California, USA) was used to confirm mitochondrial structures. Transfected cells were grown for 48 hours and fibroblasts were treated for immunofluorescence as described (20). HepG2 cells treated with $200 \mathrm{nM}$ Mitotracker® Orange for 30 mins before immunofluorescence microscopy was carried out as previously described (20), but without use of the Tritc-labeled antibody.

\section{RESULTS}

\section{Identification of a human ACOT gene cluster}

Previous data had identified six mouse Acot genes in a cluster which are located within 120 $\mathrm{kb}$ on mouse chromosome 12 D3 (15-17). Database searches using the cDNA sequences for the mouse Type-I Acot genes identified four putative human ACOT genes on chromosome 14q24.3, located within $80 \mathrm{~kb}$ of genomic sequence (Fig. 1). Based on homology to the mouse genes, we identified the putative human orthologs of Acot1, Acot2, Acot 4 and Acot6 in 
the human gene cluster. The distance between the genes is approximately $25.7 \mathrm{~kb}$ between ACOT1 and ACOT2, $16.5 \mathrm{~kb}$ between ACOT2 and ACOT4 and $16.9 \mathrm{~kb}$ between ACOT4 and ACOT6. Comparison of the two gene clusters reveals two striking differences, firstly that the order of the ACOT1 and ACOT2 genes are different in the human genome compared to mouse, and second, that the human gene cluster only contains one putative gene encoding a peroxisomal ACOT. Similar to the mouse genes, the open reading frames for three of these genes are coded for by three exons (ACOT1, ACOT2 and ACOT4) whereas the fourth gene identified in the cluster, ACOT6, contained the genomic information for all 3 exons (which would result in a full-length ACOT protein), but apparently is translated from a methionine at the end of exon 2 through exon 3. This is based on EST sequences, the estimated size of the transcript detected by Northern blot (data not shown), and the facts that we could not amplify the predicted full-length open reading frame, but we could amplify a transcript that covered part of exon 2 and exon 3.

Data base searches in the entire human genome did not indicate the presence of any other genes that would correspond to mouse Acot3 or Acot5, but a further gene was identified on chromosome 19q13.12 that shows 91\% sequence identity at nucleotide level to the ACOT4 gene on chromosome 14. However, this gene on chromosome 19 lacks introns and contains several stop codons, which will not result in active protein. Interestingly, searches in EST databases show that the pseudogene is expressed in purified pancreatic islets (EST No. CA843741, CB177282 and CA843493), brain (EST No. BI827748 and AW090080), and placenta (EST No. DB328688 and DA849162).

Alignment of the deduced amino acid sequences for the open reading frames of the ACOT1, ACOT2 and ACOT4 genes shows the striking conservation between the various ACOTs (Fig. 2). The ACOT1 and ACOT4 genes encode proteins of 421 amino acids, with the latter containing -PKL at its carboxyterminal, which is a variant of the peroxisomal type-1 targeting signal (PTS1) that can target proteins to peroxisomes (21). ACOT2 encodes a protein of 483 amino acids and contains a 62 amino acid leader sequence at the N-terminal, which targets the protein to mitochondria (see below). The 421 amino acids of ACOT2 that align to ACOT1 show $98.6 \%$ sequence identity, with only 5 amino acids being different. The three amino acids identified to be the catalytic triad of the active site in the mouse ACOT enzymes (22), a serine (acting as the nucleophile) in a Gly-X-Ser-X-Gly motif common to serine esterases, a histidine and an aspartic acid are all conserved in the human enzymes 
(indicated in Fig. 2). The serine is located at position 232 of ACOT1, the aspartic acid at 326 and the histidine at 360 .

\section{Subcellular localization of the human ACOTs}

The subcellular localization of the four human ACOTs identified in this study was examined by expression of the ACOTs in human skin fibroblasts and HepG2 cells as GFP fusion proteins. The rationale for choosing either N-terminal or C-terminal GFP was based on the presence of putative targeting signals at the $\mathrm{N}$ - or $\mathrm{C}$-terminal ends, and also on previous data obtained for localization of the mouse orthologs. The ACOT1 (homologous to the mouse ACOT1 which is cytosolic (23)) contains no apparent targeting signal but contains a PTS1like sequence of -SKV at its C-terminal end. However transfection of this GFP fusion protein into human fibroblasts resulted in a protein with a diffuse pattern of expression with no visible punctate staining, in line with a cytosolic localization (Fig. 3A). ACOT6 also contains

a PTS1-like sequence of -SKI at its C-terminal end but this GFP fusion protein was also localized in cytosol (Fig. 3B). The ACOT2 protein contains a putative mitochondrialtargeting signal at its $\mathrm{N}$-terminal end. This GFP fusion protein showed a typical pattern for mitochondrial localization as judged by immunofluorescence microscopy (Fig. 3C). Use of a mitotracker confirmed that the ACOT2 fusion protein was localized in mitochondria (Fig. 3D). The human ACOT4 contains a near-consensus PTS1 of -PKL at its C-terminal, which is also present in C. tropicalis sterol carrier protein (POX18), and has been shown to target proteins to peroxisomes (24). We transfected the ACOT4/NT-GFP vector into both control fibroblasts and fibroblasts from a Zellweger patient, which are unable to import peroxisomal matrix proteins. Using immunofluorescence microscopy for GFP detection, ACOT4 showed a punctate pattern of expression in control fibroblasts, indicative of a peroxisomal localization (Fig. 3E). However, in Zellweger fibroblasts, transfection of ACOT4 resulted in a diffuse GFP expression, showing an inability of the protein to be imported into peroxisomes (Fig. 3F).

\section{Recombinant expression and characterization of human and mouse ACOT proteins}

The cloning of the open reading frames of ACOT1 and ACOT2 into pET16b and ACOT4 into pET102 vectors resulted in expression of these proteins as His-tagged fusion proteins, to allow for purification using affinity chromatography. Following purification on a HiTrap ${ }^{\mathrm{TM}}$ column, the purified ACOT1 and ACOT2 were detected as single bands of approximately 46 
$\mathrm{kDa}$ in mass on SDS/PAGE gel stained with Coomassie Brilliant blue, whereas ACOT4 was detected as an approximately $60 \mathrm{kDa}$ band as a thioredoxin fusion protein (data not shown).

The human ACOT4 gene shows strongest similarity to ACOT4 in mouse, and is therefore likely to be the human ortholog of mouse ACOT4. The mouse ACOT4 enzyme was recently shown to be a highly specific succinyl-CoA thioesterase, with only low activity with glutarylCoA and no activity with any other tested acyl-CoAs (17). In line with this, characterization of recombinant human ACOT4 indeed showed highest activity with succinyl-CoA $\left(\mathrm{V}_{\max } \approx 581\right.$ $\mathrm{nmol} / \mathrm{min} / \mathrm{mg}$ protein, and $\mathrm{K}_{\mathrm{m}} \approx 14 \mu \mathrm{M}$ ), with much lower $\mathrm{V}_{\max }$ and higher $\mathrm{K}_{\mathrm{m}}$ with glutarylCoA (132 nmol/min/mg protein and $147 \mu \mathrm{M}$, respectively). Surprisingly, ACOT4 was also active on all long-chain saturated acyl-CoAs of $>8$ carbon atoms as well as all tested unsaturated acyl-CoAs (C18:1, C18:2 and C20:4). The calculated $\mathrm{V}_{\max }$ and $\mathrm{K}_{\mathrm{m}}$ values of ACOT4 with C14-CoA (which was the best long-chain acyl-CoA substrate) were 137 $\mathrm{nmol} / \mathrm{min} / \mathrm{mg}$ protein and $3.4 \mu \mathrm{M}$, respectively. Fig. 4A summarizes the activity of human ACOT4 with all acyl-CoAs tested, demonstrating that human ACOT4 is a succinyl-CoA thioesterase that also hydrolyzes long-chain saturated and unsaturated monocarboxylic acylCoAs. The pattern of activity of human ACOT4 mirrors the combined activities of the recently characterized mouse ACOT3, ACOT4 and ACOT5 proteins (summarized in Fig. 4B). Therefore the human peroxisomal ACOT4 can replace the function of 3 distinct peroxisomal enzymes in mouse. Interestingly, although succinyl-CoA (C4-dicarboxylylCoA) was the best substrate for ACOT4, the corresponding C4-monocarboxylyl-CoA (butyryl-CoA) was not a substrate, and in contrast the C12 dicarboxylyl-CoA was not a substrate in spite of the fact that the corresponding C12 monocarboxylyl-CoA was a good substrate (data not shown). These data demonstrate that human ACOT4 has not simply evolved into a non-specific acyl-CoA thioesterase, but rather that human ACOT4 has acquired the combined activities of mouse ACOT3, ACOT4 and ACOT5.

Kinetic characterization of recombinant human ACOT1 and ACOT2 showed very similar substrate specificities, with both enzymes being mainly active on long-chain saturated acylCoAs of 12 to 20 carbon atoms, and long-chain unsaturated acyl-CoAs such as C16:1-CoA, C18:1-CoA (Fig. 5A and B). The data thus show that ACOT1 and ACOT2 function as longchain acyl-CoA thioesterases with no detectable activity with acyl-CoAs of 8 carbon atoms or shorter. Kinetic characterization of ACOT1 and ACOT2 show that the $\mathrm{K}_{\mathrm{m}}$ for long-chain 
acyl-CoAs is in the low $\mu \mathrm{M}$ range, demonstrating that these are probably the in-vivo substrates for the enzymes (Table I).

\section{Tissue expression of human ACOTs}

Northern blot analysis was carried out to examine the tissue expression of the various human ACOTs (Fig. 6). As ACOT1 and ACOT2 in human show 99\% sequence identity to eachother, it was not possible to make a probe that would be specific for the ACOT1. Using a cDNA probe to ACOT1/ACOT2, one transcript of approximately $1.8 \mathrm{~kb}$ was detected with highest levels in heart, liver, muscle and kidney. However, a cDNA probe corresponding to the mitochondrial-targeting signal of the ACOT2 was constructed, which will distinguish between these two mRNAs. Using the ACOT2 specific probe, the mRNA signal was again strongest in heart, liver, muscle and kidney and also weakly in placenta and pancreas, suggesting that ACOT2 is much more strongly expressed than ACOT1. This is further supported by searches in the EST database, which showed that ESTs corresponding to ACOT2 were much more abundant than ESTs corresponding to ACOT1. The ACOT4 was detected as two transcripts of approximately 1.7 and $2.2 \mathrm{~kb}$, with strongest expression in liver and kidney and weaker expression in placenta, heart and muscle. These two transcripts were differentially expressed with the lower transcript expressed mainly in liver and kidney, whereas the upper transcript was detectable in heart, liver, muscle and kidney.

\section{DISCUSSION}

We have previously identified and characterized a gene cluster on chromosome 12 D3 in mouse (15-17), containing six individual genes, Acot1 (cytosolic), Acot2 (mitochondrial) and Acot3, 4, 5 and 6 (all peroxisomal). Here we have characterized the corresponding cluster in human, which consists of four ACOT genes on chromosome 14q24.3. Three of these genes, ACOT1, ACOT2 and ACOT4 encode full-length ACOT proteins, and one gene, ACOT6, is translated from a methionine at the end of exon 2 into a putative open reading frame of only 207 amino acids. Although the catalytic amino acids would be contained in the protein, it is not clear whether the protein will be active. Interestingly the mouse ACOT6 ortholog contains a canonical PTS-1 targeting signal of -SKL in the C-terminal end, which targets mouse ACOT6 to peroxisomes (Westin et al, unpublished results), while human ACOT6 ends with an isoleucine instead of leucine (C-terminal end of -SKI), which results in a 
cytosolic localization. It is remarkable that mouse contains so many peroxisomal ACOT enzymes, whereas human contains only one functional peroxisomal Type-I ACOT. However, our finding that human ACOT4 hydrolyzes succinyl-CoA, glutaryl-CoA and long-chain acylCoAs, provides a plausible explanation for the difference in the number of peroxisomal ACOTs in human and mouse. In mouse, there are three Type-I ACOT enzymes characterized to date that hydrolyze straight-chain acyl-CoA esters, the ACOT3 active on long-chain acylCoAs and the ACOT5 active on medium chain acyl-CoAs (16), together with ACOT4, a newly identified succinyl-CoA/glutaryl-CoA thioesterase (17). While mouse ACOT4 only hydrolyzes succinyl-CoA with high activity, and glutaryl-CoA with low activity, human ACOT4 also hydrolyzes saturated and unsaturated medium- to long-chain acyl-CoAs. It is therefore reasonable to suggest that human ACOT4 catalyzes the combined activities of mouse ACOT3, 4 and 5. Also, human ACOT4 is mainly expressed in liver and kidney, similar to mouse Acot3 and 4, further strengthening a functional redundancy. It would therefore be very interesting to compare this gene cluster in various species to trace the appearance/disappearence of genes in this cluster, and to follow the acquisition of the different activities in ACOT4 in higher vertebrates. A similar convergent evolution from mouse to human is seen among acyl-CoA oxidases, peroxisomal enzymes catalyzing the first reaction in the $\beta$-oxidation of various acyl-CoAs in peroxisomes. While rat and mouse have three genes encoding straight-chain acyl-CoA oxidase, trihydroxycoprostanoyl-CoA oxidase and branched-chain (pristanoyl-CoA) acyl-CoA oxidase, (25), human has only two genes encoding the straight-chain oxidase and a combined trihydroxycoprostanoyl-CoA and pristanoyl-CoA oxidase $(26,27)$. Interestingly, in human there is also an intron-less $A C O T$ pseudogene located on chromosome 19q13.12, which shows very high similarity to ACOT4. Although this pseudogene is expressed at mRNA level in several tissues, the function is not known. However, recently it was shown that a pseudogene of the Makorin 1 gene (Makorin 1-p1) could regulate the mRNA stability of its homologous coding gene (28). Therefore the ACOT pseudogene may have a regulatory function on the expression of ACOT4. The fourth gene in the ACOT gene cluster, ACOT6, contains the genetic information for all three coding exons common to the ACOT genes described in this work, however, translation apparently starts from a methionine present at the end of exon 2 . We were able to amplify a PCR product containing this truncated open reading frame of ACOT6, but it is not known whether ACOT6 is expressed as an active protein. The corresponding mouse ACOT6 gene encodes a $46 \mathrm{kDa}$ 
protein that is expressed, but as yet the substrate for this enzyme has not been defined (Westin et al, unpublished results).

Cloning and sequence analysis of ACOT1 and ACOT2 revealed open reading frames encoding proteins of 421 amino acids that aligned to eachother, with $98.6 \%$ sequence identity. While ACOT2 contains a further 62 amino acids in-frame at the $\mathrm{N}$-terminal end that functions as a mitochondrial targeting signal, ACOT1 lacks these amino acids. ACOT2 was previously cloned as a human peroxisomal acyl-CoA thioesterase named PTE2 (29), however sequence alignment of PTE2 reveals that it relates to ACOT2 without its mitochondrial targeting signal. The assignment of the name PTE2 was based on the finding that the -SKV tripeptide at the $\mathrm{C}$-terminal end acted as a weak peroxisomal targeting signal, mediating some import of this protein into peroxisomes. Indeed it has been shown that mutation of the peroxisomal targeting signal from the consensus -SKL to -SKV results in mistargeting to cytosol (30). We now show that ACOT2 contains a mitochondrial-targeting signal at its $\mathrm{N}$ terminal end, which targets the protein to mitochondria. In line with the apparent lack of targeting signals in ACOT1, the protein remained in the cytosol in the GFP experiments.

Mouse and human peroxisomes contain a further acyl-CoA thioesterase now renamed ACOT8 (previously called PTE1, hTE, hACTEIII and PTE-2) in a new acyl-CoA thioesterase nomenclature system (31), which can hydrolyze a wide variety of CoA esters, including bile acid-CoAs, branched-chain-CoAs and long- medium- and short chain acylCoAs $(20,32)$. Therefore it appears that mouse peroxisomes contain 5 different peroxisomal acyl-CoA thioesterases, hydrolyzing a broad spectrum of CoA esters, whereas human contains only 2 genes coding for peroxisomal acyl-CoA thioesterases, whose activity cover the same span of CoA ester substrates. The need for several peroxisomal ACOT enzymes with different specificities becomes evident in view of the multiple functions that peroxisomes play in chain-shortening of various carboxylic acids (as peroxisomes do not catalyze complete $\beta$-oxidation of lipids), including long- and very long-chain fatty acids, dicarboxylic acids, bile acid intermediates and xenobiotic carboxylic acids (19, 33). Furthermore, fatty acids are apparently transported across the peroxisomal membrane as CoA-esters (in contrast to mitochondria that utilizes a carnitine-acylcarnitine transport system), while fatty acid degradation products may be transported out of the peroxisome as carnitine esters, glycine or taurine conjugates or as the free acids. This implies that ACOTs 
may serve essential functions in peroxisomes to regulate $\beta$-oxidation (CoASH levels) as well as in termination of $\beta$-oxidation at various chain-lengths for exit out of the organelle. In view of this, we were surprised to only find one peroxisomal Type-I ACOT in the human genome. However, the finding here that ACOT4 in fact catalyzes the activities of three mouse ACOTs not only explains the lower number of human ACOT genes, but also underscores the physiological importance of these ACOTs in peroxisomal lipid metabolism.

ACOTs play key roles in maintaining the intracellular ratio between the CoA esters of various lipids and the free acid e.g. acyl-CoAs and free fatty acids. Putative functions for these ACOT enzymes in cytosol, mitochondria and peroxisomes have been described in detail in a recent review, mainly based on work carried out on the mouse enzymes (12). ACOT1 and ACOT2 have very similar substrate specificities, both active on long-chain acylCoAs, which is not surprising based on their extremely high level of sequence identity (>98\%). However, these enzymes show two distinct cellular localizations in cytosol and mitochondria and therefore have specific functions within these compartments in the metabolism of long-chain acyl-CoAs. In mitochondria, ACOT2 has been suggested to be involved in a co-ordinate shuttle pathway together with uncoupling protein 3 (UCP3) in muscle and brown adipose tissue (34). This hypothesis suggests that free fatty acids are shuttled out of the mitochondria by UCP3 when fatty acid $\beta$-oxidation predominates. These free fatty acids would result from the hydrolysis of acyl-CoAs by ACOT2, thus releasing $\mathrm{CoASH}$ for further reactions within the mitochondria during $\beta$-oxidation. The free fatty acids transported out of the mitochondria by UCP3 would then be reactivated by acyl-CoA synthetases to form acyl-CoAs, which could subsequently be transported back into the mitochondria as a carnitine ester via the sequential action of carnitine palmitoyl transferase I (CPTI) and the carnitine acylcarnitine (CAC) transporter. This shuttle mechanism would prevent overloading of the mitochondria with acyl-CoA and trapping of $\mathrm{CoASH}$, which is vital for $\beta$-oxidation and the citric acid cycle to proceed. A role for ACOT1 has been suggested in control of ligand supply for the PPAR family of nuclear receptors in the form of acyl-CoAs or free fatty acids and/or channeling fatty acids toward degradation rather than esterification (22).

In summary, the identification of a family of human acyl-CoA thioesterases with distinct tissue expression and substrate specificities opens up avenues for further research into these 
enzymes, which may be important in regulation of numerous intracellular processes, as well as for maintaining robustness in response to rapid changes in availability of energy substrates. Patients with lowered ACOT activity have recently been described (35), however, no patients deficient in the Type-I family of ACOT enzymes characterized in this study have yet been identified. The role of ACOT enzymes in lipid metabolism within different intracellular compartments suggests that future studies may reveal their importance in inborn errors of metabolism and lipid metabolism.

\section{REFERENCES}

1. Færgeman, N. J., and Knudsen, J. (1997) Role of long-chain acyl-CoA esters in the regulation of metabolism and in cell signalling. Biochem. J. 323, 1-12

2. Ogiwara, H., Tanabe, T., Nikawa, J., and Numa, S. (1978) Inhibition of rat-livercoenzyme-A carboxylase by palmitoyl-coenzyme A. Formation of equimolar enzymeinhibitor complex. Eur. J. Biochem. 89, 33-41

3. Thompson, A. L., and Cooney, G. J. (2000) Acyl-CoA inhibition of hexokinase in rat and human skeletal muscle is a potential mechanism of lipid-induced insulin resistance. Diabetes 49, 1761-1765

4. Srere, P. A. (1965) Palmityl-coenzyme A inhibition of the citrate-condensing enzyme. Biochim. Biophys. Acta 106, 445-455

5. Bränström, R., Aspinwall, C. A., Välimäki, S., Östensson, C.-G., Tibell, A., Eckhard, M., Brandhorst, H., Corkey, B. W., Berggren, P.-O., and Larsson, O. (2004) Longchain CoA esters activate human pancreatic beta-cell $\mathrm{K}_{\mathrm{ATP}}$ channels:potential role in Type 2 diabetes. Diabetologia 47, 277-283

6. Taylor, E. B., Ellingson, W. J., Lamb, J. D., Chesser, D. G., and Winder, W. W. (2005) Long-chain acyl-CoA esters inhibit phosphorylation of AMP-activated protein kinase at threonine 172 by LKB1/STRAD/MO25. Am. J. Physiol. Endocrinol. Metab. 288, E1055-1061

7. Kliewer, S. A., Sundseth, S. S., Jones, S. A., Brown, P. J., Wisely, G. B., Koble, C. S., Devchand, P., Wahli, W., Willson, T. M., Lenhard, J. M., and Lehmann, J. M. (1997) Fatty acids and eicosanoids regulate gene expression through direct interactions with peroxisome proliferator-activated receptors $\alpha$ and $\gamma$. Proc. Natl. Acad. Sci. U.S.A. 94, 4318-4323

8. Forman, B. M., Chen, J., and Evans, R. M. (1997) Hypolipidemic drugs, polyunstaurated fatty acids, and eicosanoids are ligands for peroxisome proliferatoractivated receptors $\alpha$ and $\delta$. Proc. Natl. Acad. Sci. U.S.A. 94, 4312-4317

9. Göttlicher, M., Widmark, E., Li, Q., and Gustafsson, J. Å. (1992) Fatty acids activate a chimera of the clofibric acid-activated receptor and the glucocorticoid receptor. Proc. Natl. Acad. Sci. U.S.A. 89, 4653-4657

10. Pawar, A., and Jump, D. B. (2003) Unsaturated fatty acid regulation of peroxisome proliferator-activated receptor alpha activity in rat primary hepatocytes. J. Biol. Chem. 278, 35931-35939

11. Hostetler, H. A., Petrescu, A. D., Kier, A. B., and Schroeder, F. (2005) Peroxisome proliferator-activated receptor $\alpha(\operatorname{PPAR} \alpha)$ interacts with high affinity and is conformationally responsive to endogenous ligands. J. Biol. Chem. 280, 18667-18682 
12. Hunt, M. C., and Alexson, S. E. H. (2002) The role acyl-CoA thioesterases play in mediating intracellular lipid metabolism. Prog. Lipid Res. 41, 99-130

13. Yamada, J. (2005) Long-chain acyl-CoA hydrolase in the brain. Amino Acids 28, 273278

14. Svensson, L. T., Alexson, S. E. H., and Hiltunen, J. K. (1995) Very long chain and long chain acyl-CoA thioesterases in rat liver mitochondria. Identification, purification, characterization, and induction by peroxisome proliferators. J. Biol. Chem. 270, 12177-12183

15. Hunt, M. C., Nousiainen, S. E. B., Huttunen, M. K., Orii, K., Svensson, L. T., and Alexson, S. E. H. (1999) Peroxisome proliferator-induced long chain acyl-CoA thioesterases comprise a highly conserved novel multi-gene family involved in lipid metabolism. J. Biol. Chem. 274, 34317-34326

16. Westin, M. A. K., Alexson, S. E. H., and Hunt, M. C. (2004) Molecular cloning and characterization of two mouse peroxisome proliferator-activated receptor alpha $(\mathrm{PPAR} \alpha)$-regulated peroxisomal acyl-CoA thioesterases. J. Biol. Chem. 279, 2184121848

17. Westin, M. A. K., Hunt, M. C., and Alexson, S. E. H. (2005) The identification of a succinyl-CoA thioesterase suggests a novel pathway for succinate production in peroxisomes. J. Biol. Chem. 280, 38125-38132

18. Wanders, R. J. A. (2004) Metabolic and molecular basis of peroxisomal disorders: A review. Am. J. Hum. Genet. 126A, 355-375

19. Wanders, R. J. A. (2004) Peroxisomes, lipid metabolism, and peroxisomal disorders. Mol. Genet. Metab. 83, 16-27

20. Hunt, M. C., Solaas, K., Kase, B. F., and Alexson, S. E. H. (2002) Characterization of an acyl-CoA thioesterase that functions as a major regulator of peroxisomal lipid metabolism. J. Biol. Chem. 277, 1128-1138

21. Lametschwandtner, G., Brocard, C., Fransen, M., Van Veldhoven, P., Berger, J., and Hartig, A. (1998) The difference in recognition of terminal tripeptides as peroxisomal targeting signal 1 between yeast and human is due to different affinities of their receptor Pex5p to the cognate signal and to residues adjacent to it. J. Biol. Chem. 273, 33635-33643

22. Huhtinen, K., O'Byrne, J., Lindquist, P. J. G., Contreras, J. A., and Alexson, S. E. H. (2002) The peroxisome proliferator-induced cytosolic type I acyl-CoA thioesterase (CTE-I) is a serine-histidine-aspartic acid alpha/beta hydrolase. J. Biol. Chem. 277, 3424-3432

23. Lindquist, P. J. G., Svensson, L. T., and Alexson, S. E. H. (1998) Molecular cloning of the peroxisome proliferator-induced 46-kDa cytosolic acyl-CoA thioesterase from mouse and rat liver. Eur. J. Biochem. 251, 631-640

24. Tan, H., Okazaki, K., Kubota, I., Kamiryo, T., and Utiyama, H. (1990) A novel peroxisomal nonspecific lipid-transfer protein from Candida tropicalis. Gene structure, purification and possible role in beta-oxidation. Eur. J. Biochem. 190, 107112

25. Schepers, L., Van Veldhoven, P. P., Casteels, M., Eyssen, H. J., and Mannaerts, G. P. (1990) Presence of three acyl-CoA oxidases in rat liver peroxisomes. An inducible fatty acyl-CoA oxidase, a noninducible fatty acyl-CoA oxidase, and a noninducible trihydroxycoprostanoyl-CoA oxidase. J. Biol. Chem. 265, 5242-5246

26. Baumgart, E., Vanhooren, J. C., Fransen, M., Marynen, P., Puype, M., Vanderkerckhove, J., Leunissen, J. A., Fahimi, H. D., Mannaerts, G. P., and Van Veldhoven, P. P. (1996) Molecular characterization of the human peroxisomal branched-chain acyl-CoA oxidase: cDNA cloning, chromosomal assignment, tissue 
distribution, and evidence for the absence of the protein in Zellweger syndrome. Proc. Natl. Acad. Sci. U.S.A. 93, 13748-13753

27. Vanhove, G. F., Van Veldhoven, P. P., Fransen, M., Denis, S., Eyssen, H. J., Wanders, R. J. A., and Mannaerts, G. P. (1993) The CoA esters of 2-methyl-branched chain fatty acids and of the bile acid intermediates di- and trihydroxycoprostanic acids are oxidized by one single peroxisomal branched chain acyl-CoA oxidase in human liver and kidney. J. Biol. Chem. 268, 10335-10344

28. Hirotsune, S., Yoshida, N., Chen, M., Garrett, L., Suglyama, F., Takahashi, S., Yagami, K. I., Wynshaw-Goris, A., and Yoshiki, A. (2003) An expressed pseudogene regulates the messenger-RNA stability of its homologous coding gene. Nature 423, 91-100

29. Jones, J. B., and Gould, S. J. (2000) Identification of PTE2, a human peroxisomal long-chain acyl-CoA thioesterase. Biochem. Biophys. Res. Commun. 275, 233-240

30. Gould, S. J., Keller, G. A., Hosken, N., Wilkinson, J., and Subramani, S. (1989) A conserved tripeptide sorts proteins to peroxisomes. J. Cell Biol. 108, 1657-1664

31. Hunt, M. C., Yamada, J., Maltais, L. J., Wright, M. W., Podesta, E. J., and Alexson, S. E. H. (2005) A revised nomenclature for mammalian acyl-CoA thiosterases/hydrolases. J. Lipid Res. 46, 2029-2032

32. Jones, J. M., Nau, K., Geraghty, M. T., Erdmann, R., and Gould, S. J. (1999) Identification of peroxisomal acyl-CoA thioesterases in yeast and human. J. Biol. Chem. 274, 9216-9223

33. Suga, T. (2003) Drug metabolism in peroxisomes: Involvement of peroxisomal $\beta$ oxidation system in the oxidative chain-shortening of xenotiobic acyl compounds. Drug Metab. Pharmacokin. 18, 155-162

34. Himms-Hagen, J., and Harper, M. E. (2001) Physiological role of UCP3 may be export of fatty acids from mitochondria when fatty acid oxidation predominates: an hypothesis. Proc. Soc. Exp. Biol. Med. 226, 78-84

35. Hunt, M. C., Ruiter, J., Mooyer, P., van Roermund, C. W., Ofman, R., Ijlst, L., and Wanders, R. J. A. (2005) Identification of fatty acid oxidation disorder patients with lowered acyl-CoA thioesterase activity in human skin fibroblasts. Eur. J. Clin. Invest. 35, 38-46 


\section{ACKNOWLEDGEMENTS}

This study is supported by AFA sjukförsäkrings jubileumsstiftelse, Svenska Sällskapet för Medicinsk Forskning, The Swedish Research Council, FP6 European Union Project 'Peroxisome' (LSHG-CT-2004-512018), Åke Wibergs stiftelse, Hjärt-Lungfonden, Lars Hiertas Minne, Fredrik och Ingrid Thurings Stiftelse, Ruth och Richard Julins Stiftelse, Stiftelsen Professor Nanna Svartz fond, the National Network for Cardiovascular Research (Sweden), The Swedish Heart and Lung Foundation and Stiftelsen Goljes minne. We thank Bengt Frode Kase for Zellweger fibroblasts.

Abbreviations: ACOT, acyl-CoA thioesterase; BSA, bovine serum albumin; GFP, green fluorescent protein; PTS1, peroxisomal type-1 targeting signal;

The sequences presented in this paper can be found under Accession Nos. DQ082754, DQ082755, NM_152331 and DQ082756. 


\section{FIGURE LEGENDS}

Fig. 1. Organization of the human and mouse ACOT gene clusters. Analysis of human genomic DNA sequences was carried out as described in 'Materials and Methods'. The localization of the four ACOT genes is shown on chromosome 14q24.3. The open reading frames for ACOT1, ACOT2 and ACOT4 are encoded for by three exons, whereas ACOT6 is encoded from a methionine at the end of exon 2. The ACOT gene cluster in mouse consists of six genes, Acot1-6. Note the different order of the Acot1 and Acot2 genes in mouse compared to human, and that the cellular localization for each gene product is indicated. The open square on mouse and human ACOT2 indicate the presence of N-terminal mitochondrial targeting signals.

Fig. 2. Sequence alignment of human ACOTs. Alignment of human ACOT1, ACOT2 and ACOT4 was performed using Clustal X. The individual exon boundaries for the ACOTs are indicated. ACOT2 contains a 62 amino acid mitochondrial targeting signal at its N-terminal end. The active site serine, conserved in a Gly-X-Ser-X-Gly motif, the histidine, and the aspartic acid residues of the catalytic triad are all indicated with black arrowheads.

Fig. 3. Intracellular localization of human ACOTs. Human skin fibroblasts were transfected with plasmids that expressed GFP fusion proteins of ACOT1, ACOT4 and ACOT6 and HepG2 cells were tranfected with a GFP fusion protein plasmid of ACOT2. Cells were fixed and processed for immunofluorescence microscopy. The distribution of ACOT1 and ACOT6 was examined in control fibroblasts using a Tritc-labelled anti-GFP antibody. ACOT2 localization was examined in HepG2 cells and Mitotracker® Orange CMTMRos was used to confirm mitochondrial structures. (A) ACOT1, (B) ACOT6 (C) ACOT2, (D) Mitotracker CMTMRos. The distribution of ACOT4 was investigated in fibroblasts from a control subject (E) and in fibroblasts from a Zellweger patient (F).

Fig. 4. Human ACOT4 catalyzes the combined activities of mouse ACOT3, ACOT4 and ACOT5. (A) Expression of recombinant human ACOT4 in pET102 was induced as described in 'Materials and Methods'. The substrate specificity for purified human ACOT4 was examined with various CoA esters and measured at $25 \mu \mathrm{M}$. (B) The figure shows the specific activities of mouse ACOT3, ACOT4 and ACOT5 on various acyl-CoAs measured at 
$25 \mu \mathrm{M}$ substrate concentration. Note that the activities of the monocarboxylic acyl-CoAs of ACOT3 and ACOT5 are shown in stack columns. Dicarboxylic acids; C4, succinyl-CoA; C5, glutaryl-CoA.

Fig. 5. Acyl-CoA substrate specificities of human ACOT1 and ACOT2. Human ACOT1 and ACOT2 were expressed in BL21(DES3)pLysS cells and purified as described in 'Materials and Methods'. The purified recombinant proteins were used to measure thioesterase activity with various acyl-CoAs at $15 \mu \mathrm{M}$. (A) ACOT1 (B) ACOT2.

BSA:acyl-CoA in a molar ratio of 1.8:1 was used in measuring C18-CoA thioesterase activity.

Fig. 6. Tissue expression of human ACOTs. Northern blot analysis was carried out on a Human Multiple Tissue Blots using $\alpha-32$ P-labeled cDNA probes for ACOT1, ACOT2 and ACOT4 as described in 'Materials and Methods'. 
Table I. Recombinant human ACOT1 and ACOT2 were purified and characterized for acylCoA thioesterase activity with various acyl-CoAs. $\mathrm{K}_{\mathrm{m}}$ and $\mathrm{V}_{\max }$ values were calculated using the Sigma Plot or GraphPad Prism 4 enzyme kinetics programs. $\mathrm{K}_{\mathrm{m}}$ and $\mathrm{V}_{\max }$ values were determined for saturated acyl-CoAs on two different protein preparations, and data are shown as mean \pm range of two experiments. Activity was measured on unsaturated acyl-CoAs using one protein preparation.

\begin{tabular}{|l|l|l|l|l|}
\cline { 2 - 5 } \multicolumn{1}{c|}{} & \multicolumn{2}{c|}{ ACOT 1 } & \multicolumn{2}{c|}{ ACOT2 } \\
\hline Acyl-CoA & $\begin{array}{l}\mathrm{K}_{\mathrm{m}} \\
(\mu \mathrm{M})\end{array}$ & $\begin{array}{l}\mathrm{V}_{\max } \\
(\mathrm{nmol} / \mathrm{min} / \mathrm{mg})\end{array}$ & $\begin{array}{l}\mathrm{K}_{\mathrm{m}} \\
(\mu \mathrm{M})\end{array}$ & $\begin{array}{l}\mathrm{V}_{\max } \\
(\mathrm{nmol} / \mathrm{min} / \mathrm{mg})\end{array}$ \\
\hline C10 & $35.8 \pm 5.2$ & $224 \pm 50$ & $40.3 \pm 0.7$ & $212 \pm 26$ \\
\hline C12 & $3.6 \pm 1.0$ & $700 \pm 152$ & $8.9 \pm 0.2$ & $681 \pm 94$ \\
\hline C14 & $2.8 \pm 0.2$ & $912 \pm 199$ & $1.6 \pm 0.0$ & $766 \pm 155$ \\
\hline C16 & $3.6 \pm 2.6$ & $691 \pm 42$ & $2.0 \pm 0.6$ & $656 \pm 3$ \\
\hline C18 & $2.4 \pm 0.6$ & $597 \pm 145$ & $2.8 \pm 1.6$ & $488 \pm 122$ \\
\hline C20 & $2.0 \pm 0.2$ & $520 \pm 41$ & $4.8 \pm 2.0$ & $408 \pm 64$ \\
\hline & & & & 661 \\
\hline C16:1 & 2.4 & 577 & 4.5 & 304 \\
\hline C18:1 & 4.1 & 258 & 6.1 & 418 \\
\hline C18:1 trans & 2.1 & 309 & 4.3 & \\
\hline
\end{tabular}




\section{Human}

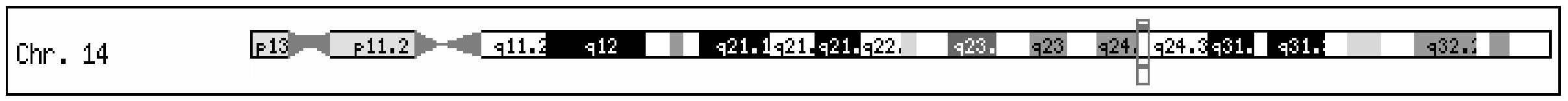
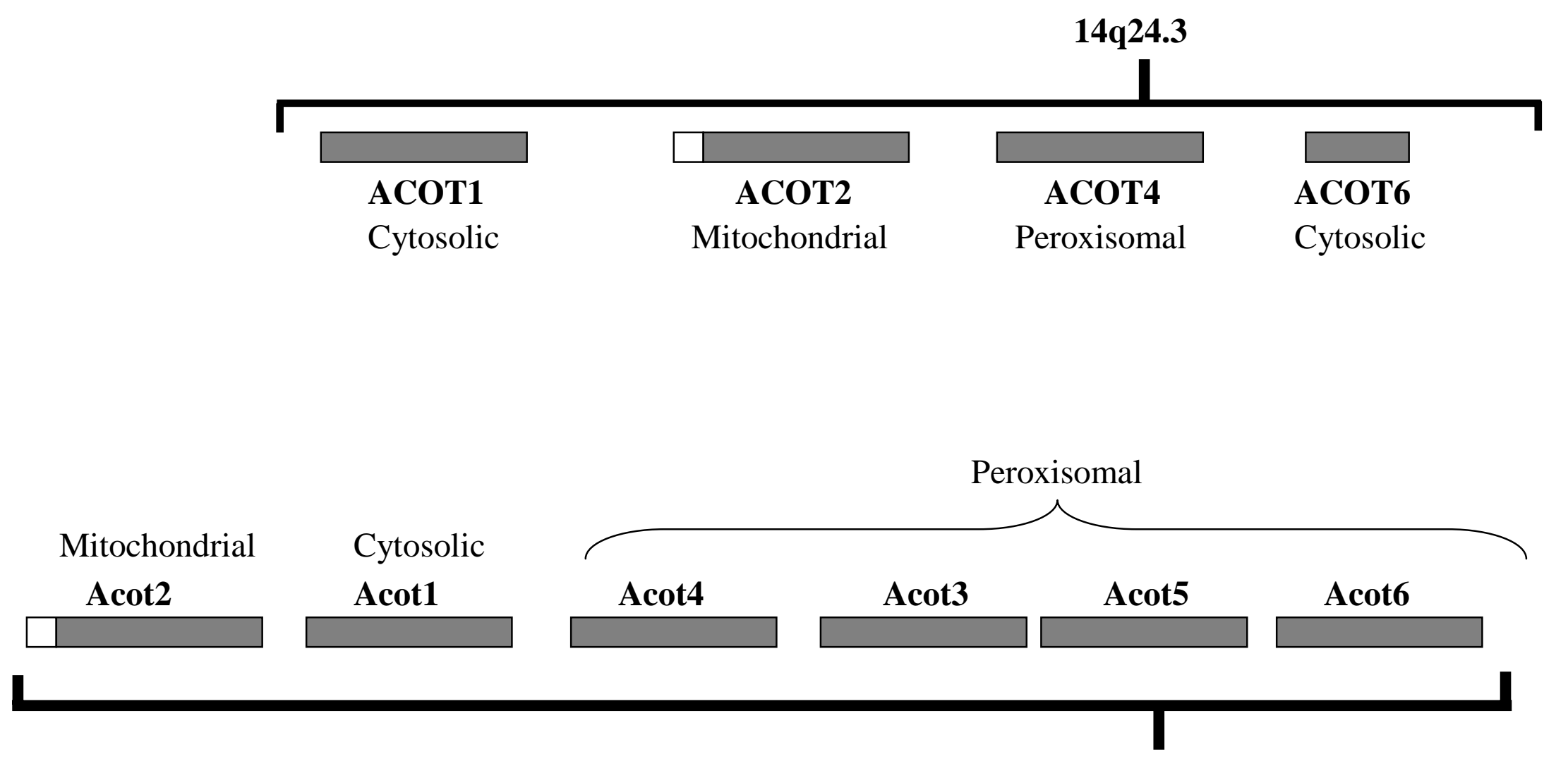

12 D3

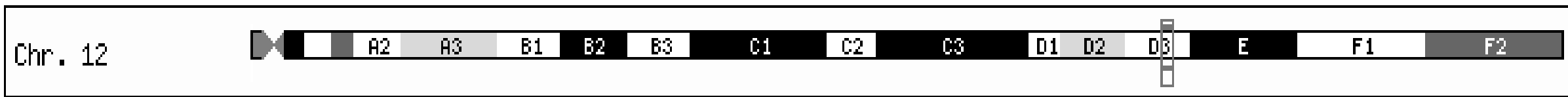

\section{Mouse}




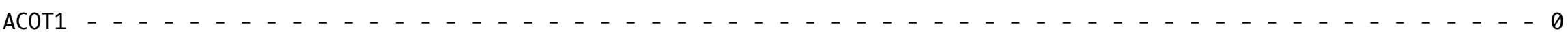
ACOT2 M S N K L L S P H P H S V V L R SEFKMASSPA VLRA SR L Y O W S L K S S A O F L G S P O L R O V G 0 I I 57

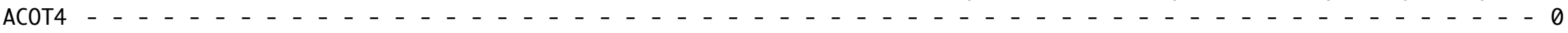

ACOT1 - - - - MA A T L I LEPAGRC CW D E PVR I AVRGLAPEQPVTLRASLRDEKGALFQAHAR Y 52

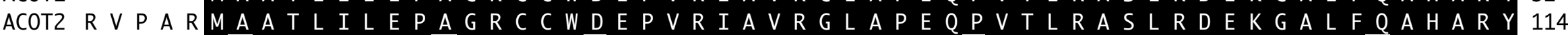

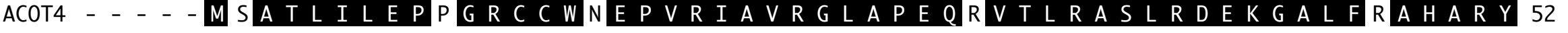

ACOT1 R A D T L GE L D LER A P A L G G S F A LEPMGLLWALEPE K P LVRLV K R DVR TPLAVELEVL 109 ACOT2 R A D T L G E D LER A P A L G G F A G LEPMGLLWALEPEKPLVRLVKRDVRTPLAVVLEVL 171 ACOT4 CA DARGELDLER A P A G GSFAGLEPMGLLWALEPEKPFWRFLKRDVQIPFVVELEVL 109 Exon 1 Exon 2

ACOT1 D G H D P D P GRLLCRVRHER Y F L P P GVRR E P VRAGRVRG T L F L P P E P G P F P G I V D M F G T 166 ACOT2 D G H D P D P GRLLCQTRHER Y F L P G VRREPVRVGR VRGTLFLPPEPGPF P G I D M F G T 228

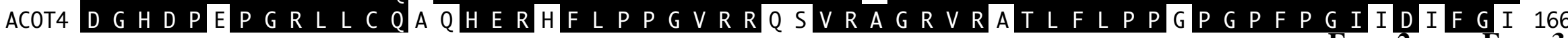
Exon 2 Exon 3 AC0T1 G G G L LE Y R A S L L A G K G F A V M A L A Y Y N Y E D L P K T ME T L H L E Y F E E A V N Y L L S H P E V K G 223 ACOT2 G G GLLEYRASLLAGKGFAVMALAYYNYEDLPKTMETLHLEYFEEAMNYLLSHPEVKG 285 ACOT4 G G GLLEYRASLLAGHGFATLALAYYNFEDLPNNMDNISLEYFE AVCYMLQHPQVKG 223 AC0T1 P G V GLLG I SKG GELCLSMASFLKG I TAAVVINGSVANVGGTLRYKGETLPPVGVNRN 280 ACOT2 P G V GLLGISKGGELCLSMASFLKGITAAVVINGSVANVGGTLRYKGETLPPVGVNRN ACOT4 P G I GLLG I S LGA D I C L S M A S F L K N V S A T VS I N G S G I S G N T A I N Y K H S S I P P L G Y D L R 280 ACOT1 R I K V T K D G Y A D I V D V L N S P LE G P D Q K S F I P VERAESTFLFLVG Q D D H N W K SE F Y A N E 337

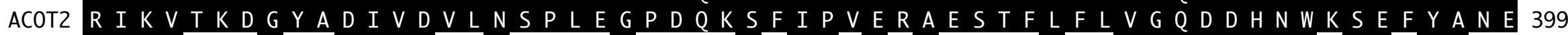

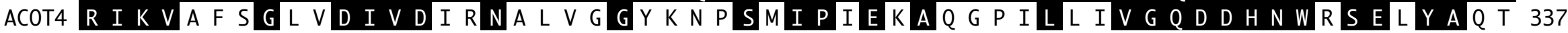

ACOT1 A C K R L Q A H GR R K P Q I I C Y P E T G H Y I E P P Y F PLCRASL HALVGSP I I W G G E P R A H A M A 394 ACOT2 A CKRLQAHGRRKPQI I C Y PETGHYIEPPYFPLCRASLHALVGSPII W G G PR A H A M A 456 ACOT4 VSERLQAHGKEKPQI I C Y PGTGHYIEPPYFPLCPASLHRLLNKHVI W G GE PRA HSKA 394

ACOT1 Q V D A W K Q L Q T F F H K H L G G HE G T I P S K V ACOT2 Q V D A W K O L O TFFHKH L G GHEG T I P S K V ACOT4 Q EDA W K Q I L A F FCK H L G GT Q K T A V P K L 
Hunt et al

Fig. 3

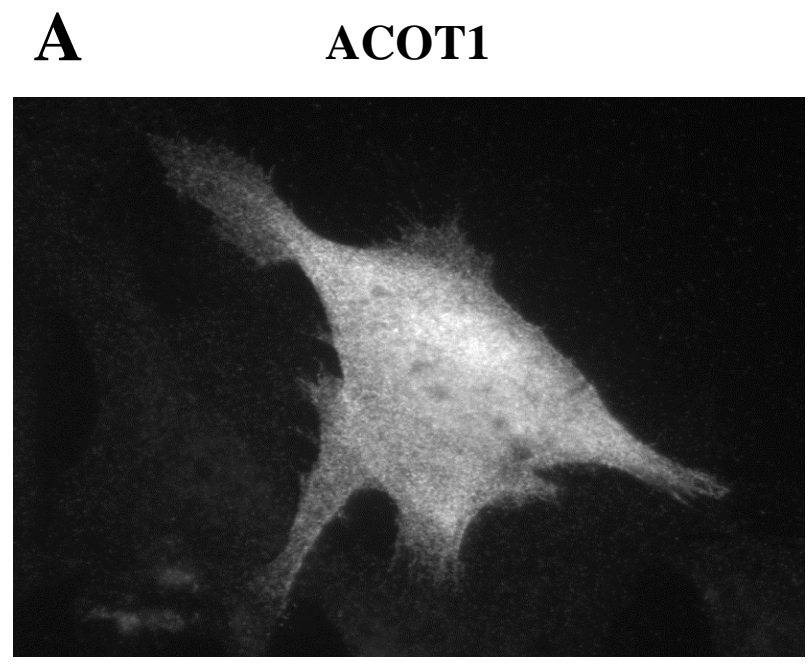

\section{B}

ACOT6

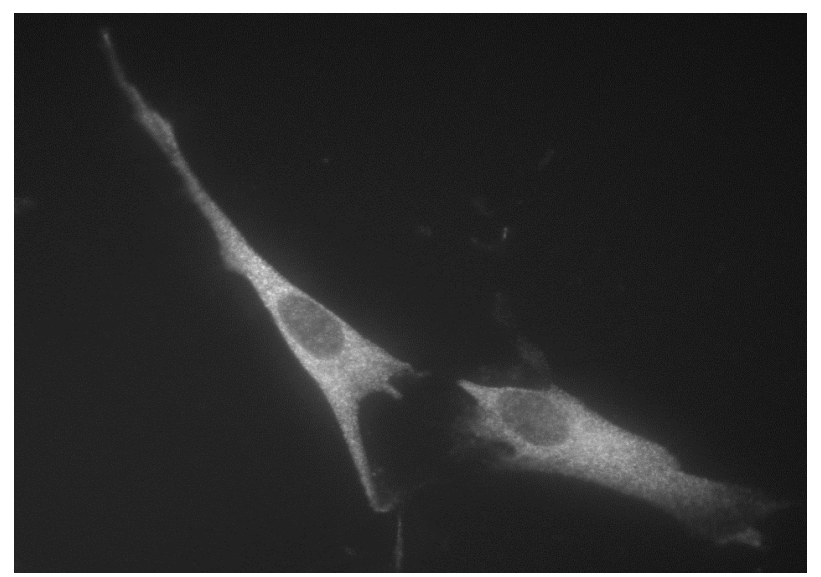

C

ACOT2

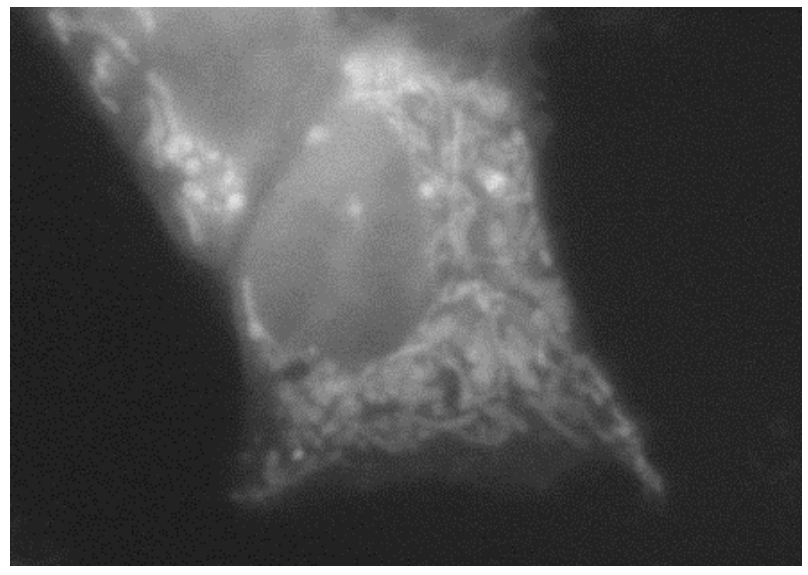

E ACOT4 - Control

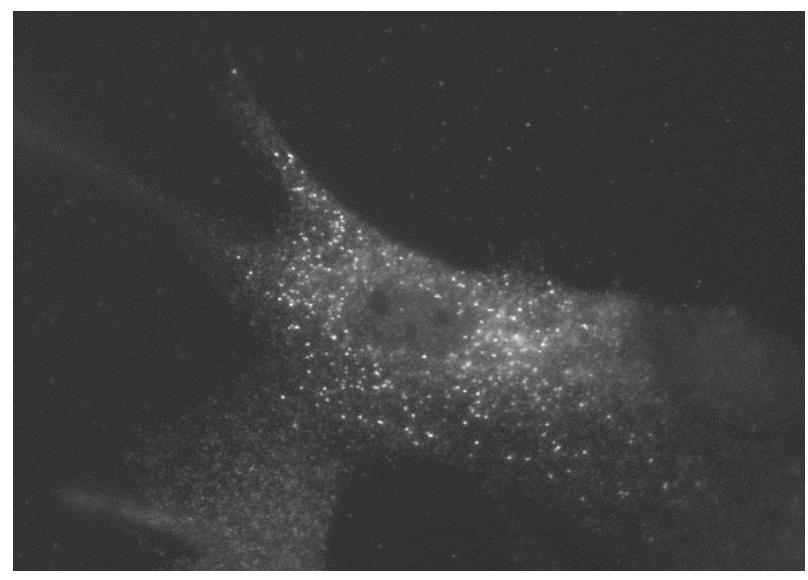

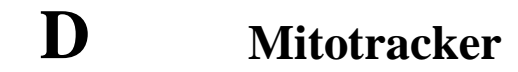

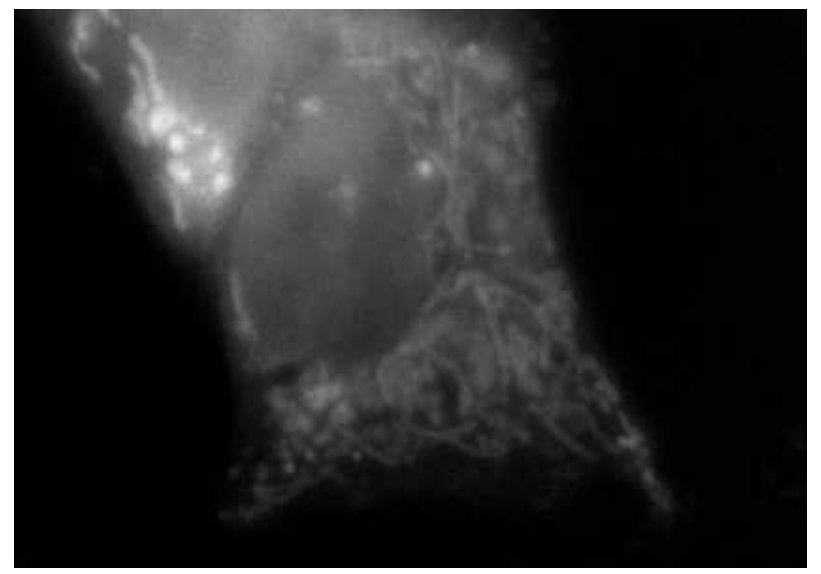

F

ACOT4 - Zellweger 


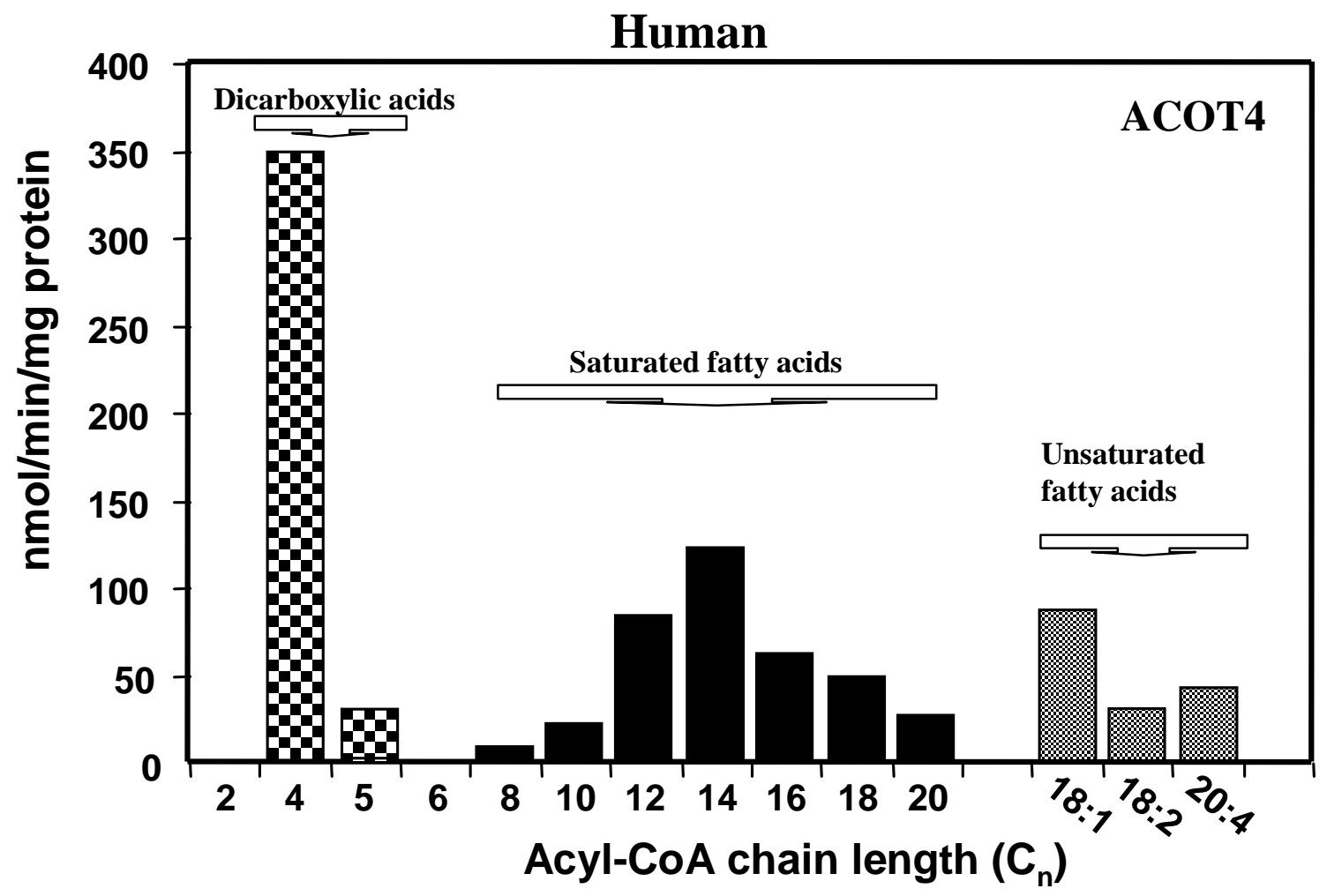

B

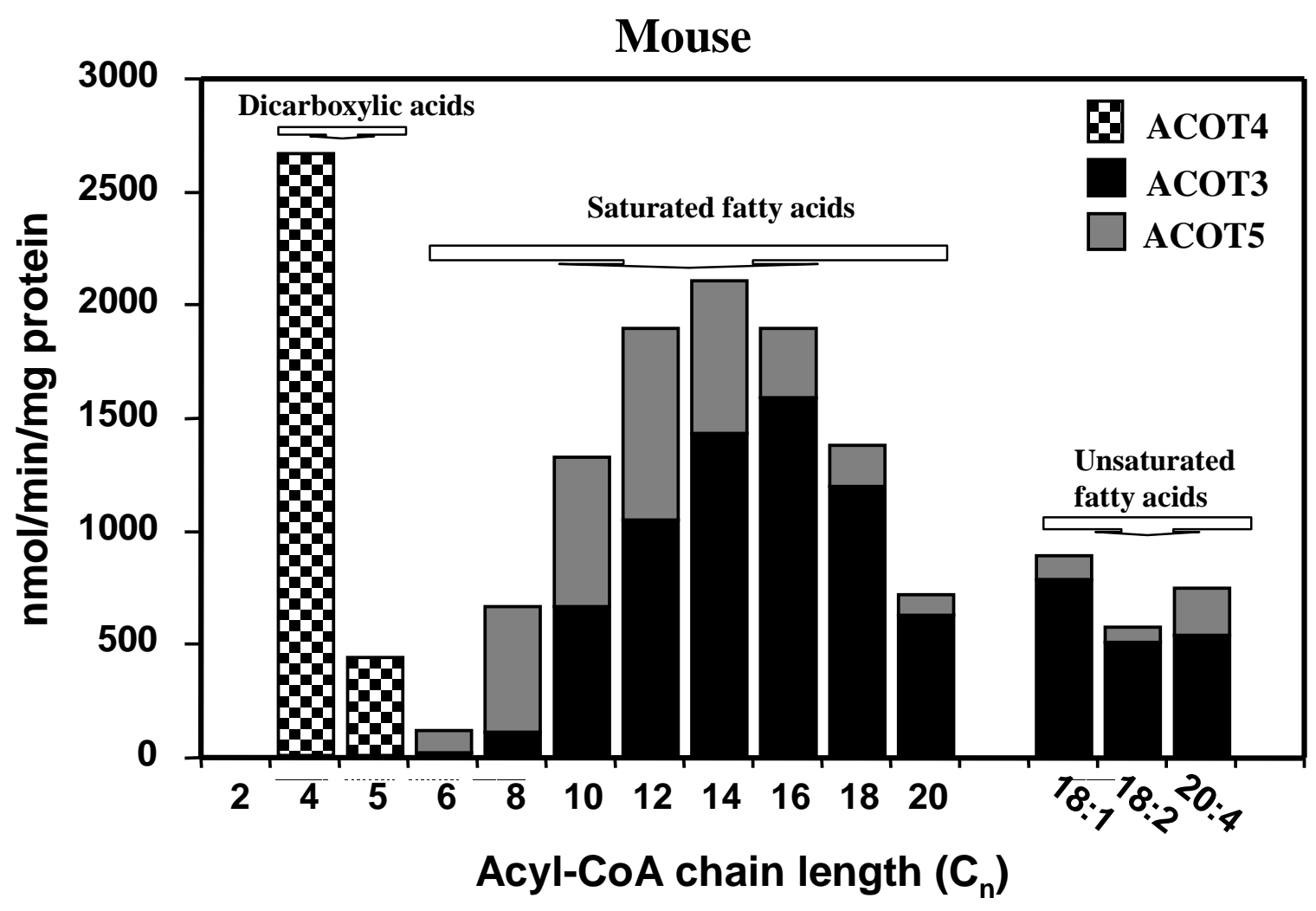


Hunt et al

Fig. 5

A

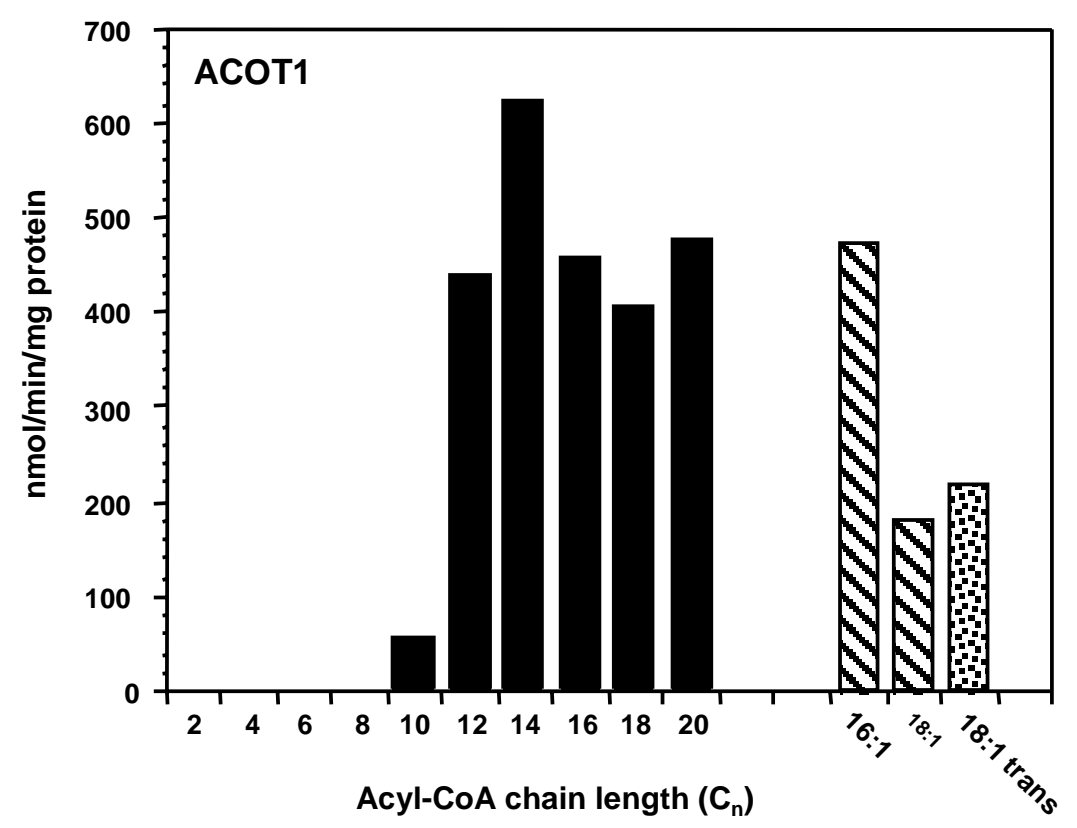

B

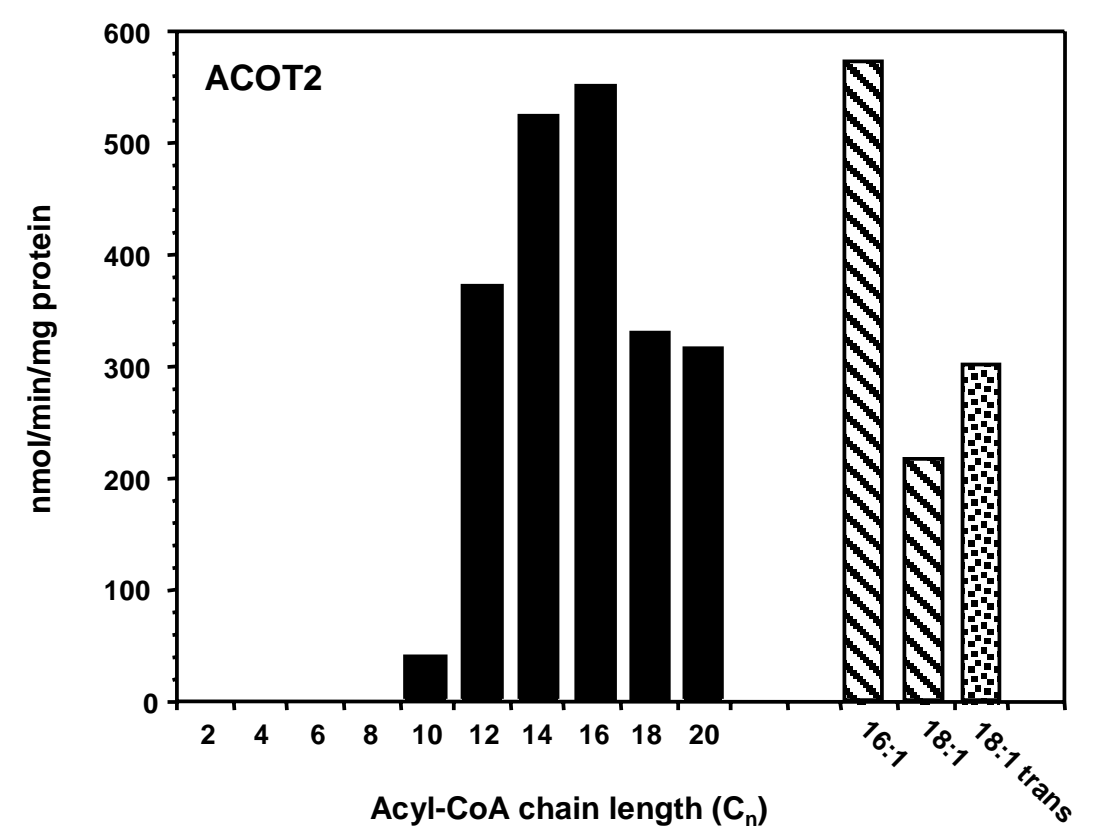




$$
\text { 产 }
$$
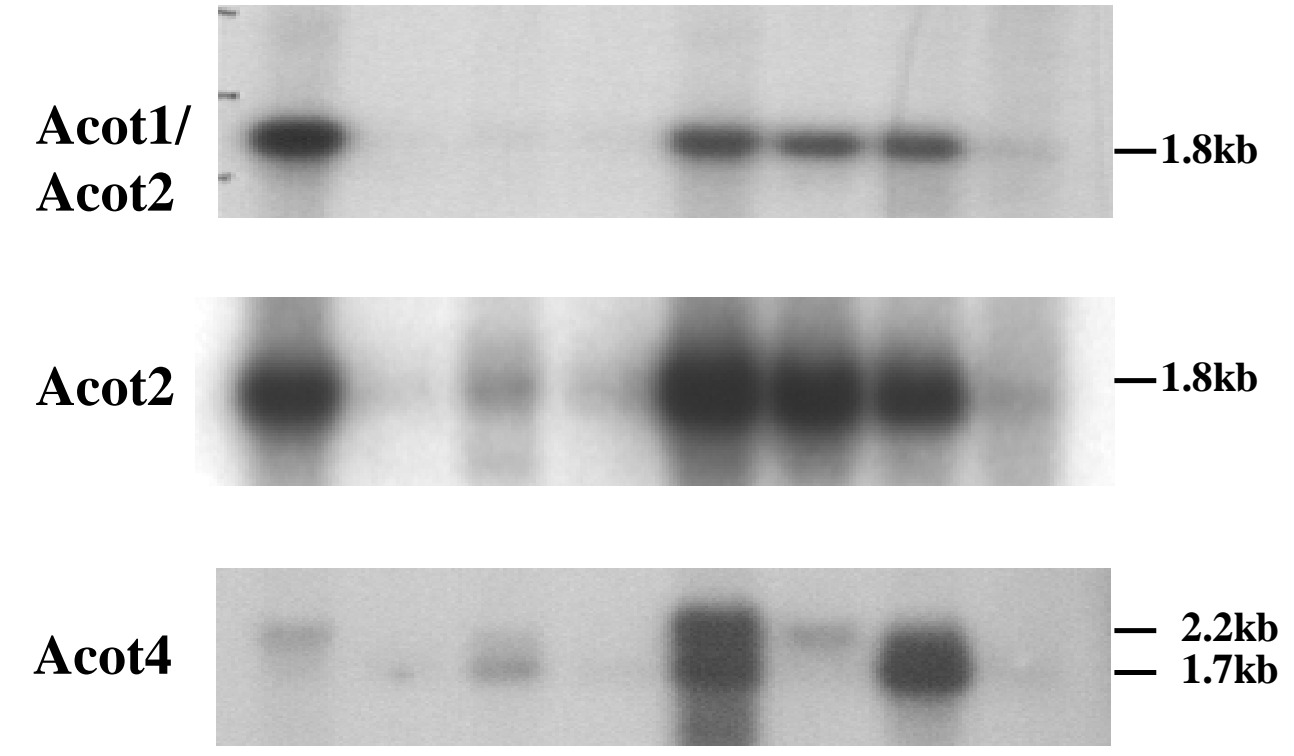